\title{
Science in the Times of SARS-CoV-2
}

\author{
Stjepan Orešković and Sebastian Porsdam Mann
}

\subsection{INTRODUCTION}

The post-World War II world has seen huge progress in scientific research. The generators have been large-scale projects funded by national governments, big business and global corporations, individual talent, and initiatives creating thousands of technology spin-offs and innovative start-ups. The role of organized knowledge in society has never been more important and the impact of STEM (Science, Technologies, Engineering, Mathematics) on people's everyday lives is growing. New scientific and technological fields as diverse as biotechnology and nanotechnology, gene therapy and pharmacogenomics, membrane technology, neural computing, nanotechnology, and ICTs in general are creating a basis for a society in which the "creation, dissemination, and utilization of information and knowledge has become the most important factor of production."

Consequently, the quantity and quality of scientific inputs and outputs, as measured by the Nature Science Index, ${ }^{2}$ have increased. Applied science is flourishing. Its outputs are tangible and evident in the areas of science, technology development, and innovation (STDI), as measured by the Global Innovation Index. ${ }^{3}$ IBM researchers estimate that 90 percent of the world's data have been created in the last two years: more data than was created in the entire previous history of the human race. $^{4}$

For the first time in the history of science, including the history of data science itself, we are witnessing a paramount attempt to integrate all existing and possible sources of data, information, and knowledge, to confront a single phenomenon: the SARS-CoV-2 pandemic.

1 Knowledge society. www.encyclopedia.com/social-sciences/applied-and-social-sciences-magazines /knowledge-society.

2 Nature Index. www.natureindex.com/country-outputs/generate/All/global/All/score.

3 Global Innovation Index. www.globalinnovationindex.org/gii-2o19-report\#.

4 IBM Watson. Big data: Big Challenge or Big Opportunity. www.ibm.com/watson/infographic/discov ery/big-data-challenge-opportunity/. 
The long-lasting linear growth of science and its impact on societies beginning in the aftermath of WWII received a major structural blow on January 7, 2020, in the city of Wuhan. Public health authorities identified a novel coronavirus. Wuhan was placed under quarantine within days and, on January 31, the World Health Organization declared a public health emergency.

The figures ${ }^{5}$ of more than 130 million cases and more than 2.8 million deaths globally convey neither the inevitable final death toll and suffering, nor the overall effect of COVID-19 on mortality. The Institute for Health Metrics and Evaluation (IHME) projection, that was based on current projections scenario, by July 1, 2021 we will see 4,4 millions COVID-19 deaths globally ${ }^{6}$ The broader disruption caused by COVID-19 could result in many additional deaths that are not directly attributable to the spread of the virus. Declines in households' economic wellbeing and changes of prioritization in access to health services for non-COVID illnesses will cause many additional deaths yet to be recorded. Credible and reliable estimates of the overall effect of the COVID-19 epidemic on health outcomes will not be available before the end of the year $2021^{7}$. and long-lasting problems from COVID-19 make it even more important to reduce the spread of the disease ${ }^{8}$.

As the SARS-CoV-2 virus started to spread in humans and the COVID-19 epidemics/pandemics emerged, global society rapidly experienced a deluge of controversial if not contradictory data concerning scientific facts, governmental evidence-based policies, as well as health and security intelligence. ${ }^{9}$ In a global pandemic situation, data are an essential tool for making decisions concerning the allocation of resources as well as for measuring the effectiveness of interventions. Many significant and basic facts about COVID-19 are still missing, including the most important one: how many people have been infected so far? Without reliable virological testing data, we cannot develop epidemiological projections and models accurately. ${ }^{10}$ Without having exact data on the total number of people infected we also cannot precisely calculate the

5 All country-specific figures and numbers in the chapter are taken from the Johns Hopkins COVID-19 Dashboard, accurate as of June 14, 2020. Johns Hopkins University Medicine. COVID-19 Dashboard by the Center for Systemic Science and Engineering (CSSE) at Johns Hopkins University. https://corona virus.jhu.edu/data/mortality. Figures for GDP are from World Bank Data, see 13010.1 for sources.

6 The Institute for Health Metrics and Evaluation. Covid-19 projections. https://covidıp.healthdata.org /global?view=total-deaths\&tab=trend

7 World Health Organization. The true death toll of COVID-19: Estimating global excess mortality. Available at: https://www.who.int/data/stories/the-true-death-toll-of-covid-19-estimating-global-excessmortality

8 Mayo Clinic. Covid-19 (coronavirus): Long term effects. https://www.mayoclinic.org/diseasesconditions/coronavirus/in-depth/coronavirus-long-term-effects/art-20490351

9 S. Herman and J. Seldin. Trump Contradicts US Intelligence; Says COVID-19 Came From Chinese Lab. Updated May 1, 2020 o9:40 AM. Available at: www.voanews.com/covid-19-pandemic/trumpcontradicts-us-intelligence-says-covid-19-came-chinese-lab.

10 Without knowing how many people are being infected we cannot get a credible calculation of any other key epidemic parameters such as attack the rate/ratio, the reproduction rate (the average number of people an infectious person is expected to infect in an entirely susceptible population mathematically defined as follows: Ro $=\beta{ }^{*} \kappa$ * D in which $\beta$ is the risk of transmission per contact, $\mathrm{K}$ is the contact rate, and $\mathrm{D}$ is the duration of infectiousness). 
case-fatality rate (CFR) (the percentage of patients with the disease (cases) who die from the condition), which likely ranges widely with covariates.

This is an important problem. Knowing the number of deaths during a period of the pandemic is not enough. Moreover, in many cases, we cannot even rely on simple and standard measures such as the mortality rate which countries are reporting to the World Health Organization. We need these measures to calculate excess deaths/excess mortality rates. These rates compare the number of deaths during a period of the pandemic with the average number of deaths during the same period in previous years, thus unmasking potential hidden effects. ${ }^{11}{ }^{12}$ Thus, in the period between 26 January and 3 October 2020 , the US registered 360,000 deaths in excess of the five-year average, ${ }^{13}$ of which 209,000 cases were confirmed to be due to COVID-19. The same trend applied for all G-8 countries, although following a different cycles, different seasonal patterns and strong difference in intensity.

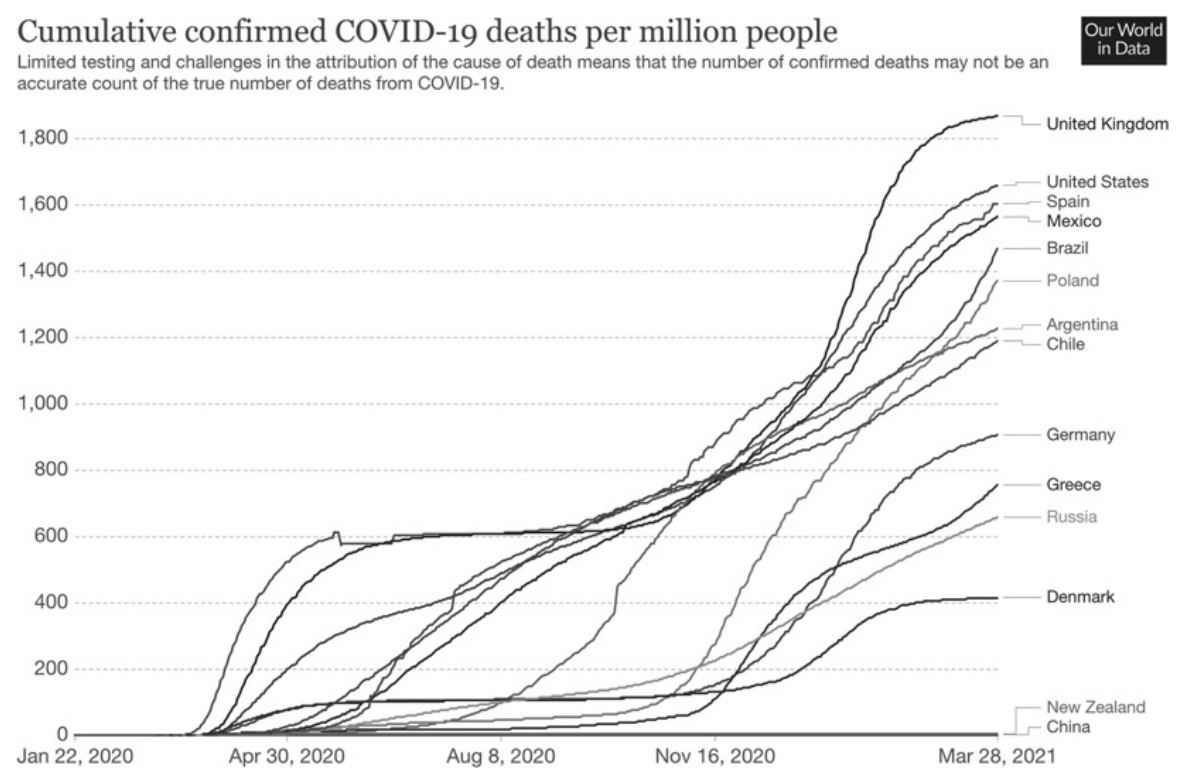

Figure 10.1 Excess mortality during COVID-19 Pandemic: Deaths from all causes compared to previous year, all ages in G-8 Countries

${ }^{11}$ The mortality rate is the number of people who died in a defined population for a given time interval expressed as number of deaths per 100,000 people.

12 J. Wu, A. McCann, J. Katz, and A. Peltier, A. 87,000 Missing Deaths: Tracking the True Toll of the Coronavirus Outbreak. New York Times, Updated May 28, 2020, 12:30 P.M. E.T. available at: www .nytimes.com/interactive/2020/04/21/world/coronavirus-missing-deaths.html.

13 Center for Disease Control and Prevention. Excess Deaths Associated with COVID-19, by Age and Race and Ethnicity - United States, January 26-October 3, 2020. Available at: https://www.cdc.gov/ mmwr/volumes/69/wr/mm6942ez.htm 
Not all excess deaths should be directly attributed to the COVID-19 pandemic. Lives will be lost because of interactions with other illnesses, the necessary reduction in the quality and magnitude of medical care for everyone else implied by the vast resource drain of COVID-19, as well as factors such as domestic violence. These facts stress the importance of the distinction between death "with" or "from" COVID-19.

Notwithstanding the profound uncertainty and questionable credibility of the available data, specific numbers and statistics are being presented by scientists, the media, and governments with the appearance of conviction and certitude. However, incomplete or incorrect data may create or contribute to false senses of security, or alternatively to anxiety and even social hysteria. Far-fetched, exaggerated or manipulated information derived from questionable data have already generated serious scientific and policy mistakes in relation to the appropriate separation and restriction of movement of individuals exposed to a contagious disease (sc. quarantine, selfquarantine, and isolation.) Such measures, as well as their society-wide analogues of lockdown and social distancing, are known from previous experience to be the single most effective set of public health measures. By "flattening the curve," these triedand-tested methods reduce the burden incumbent on healthcare systems at any specific time point, thereby preventing the most serious collateral iatrogenic damage resulting from the pressure on overburdened and under-resourced medical staff and facilities. However, without reliable data specifically relevant to the COVID-19 pandemic, efficacious and evidence-based social distancing policies cannot be established, but must rather be approximated. The severity of the ethical implications of this lack of data integrity and availability may be appreciated by considering their direct translatability into lives not saved, avoidable illnesses, and unnecessary public resource drainage.

This chapter demonstrates the utility and validity of applying a human rights lens to topical and important issues in science and society through an in-depth case study of the current SARS-COVID-2 pandemic. After setting out the relevant background, recent developments in the scientific fight against the pandemic are considered in light of the provisions of Article 15 ICESCR and 27 UDHR, which enshrine the human right to enjoy the benefits of scientific progress and its applications. This right is relevant to several aspects of the scientific process, from funding, data acquisition, hypothesis selection and experimentation all the way through to publication, knowledge sharing and the implementation of resulting knowledge in the spheres of policy and technology. ${ }^{14}$

14 On the right to science and its relevance to science and society, see S. Porsdam Mann, Y. Donders, C. Mitchell, V. J. Bradley, M. F. Chou, G. Church, H. Porsdam. "Advocating for science progress as a human right." PNAS 115(42), pp. 10820-23 and S. Porsdam Mann, H. Porsdam, Y. Donders "Sleeping Beauty: The right to science as a global ethical discourse." Human Rights Quarterly $42(2)$ $332-356$. 
The second half of the chapter focuses on a highly pertinent yet little-discussed dimension of scientific research: the speed at which it is conducted. The analysis proceeds by way of analogy to the central thesis of Nobel Laureate Daniel Kahneman's summary of decades of research into heuristics and biases, Thinking, Fast and Slow. ${ }^{15}$ It is suggested that the dichotomy between a "fast," instinctive and affective cognitive process and its "slow," logical, and deliberative counterpart also accurately characterizes two idealized, diametrically opposed and extreme approaches to the scientific process. Nowhere is this distinction of greater practical significance than in the contemporary response to the SARS-CoV-2 pandemic.

The ongoing threat to human life and progress, the constant attention from the media and the public, as well as the possibility of glory for major advances, all affect scientists and their work. While this enables practical cooperation and reduces the timeframe for possible breakthroughs to such an extent as to offer hope to individuals currently suffering under the burden of the disease, these same factors likely introduce the very heuristics and biases that the scientific method is supposed to rule out or minimize. From an abstract, collective and long-term perspective, nothing beats "slow," curiosity-driven and methodologically unimpeachable research based on a rigorous understanding of the scientific method. Yet the price paid for greater certainty is greater latency, and in the case of the SARS-CoV-2 pandemic, time is already running short for hundreds of thousands of infected individuals.

Building on this discussion, the importance of trust in science and in evidence are underlined, and the argument advanced that the "right to science lens" provides a useful framework for identifying the elements necessary for such trust, and offers guidance as to how it is best achieved. We argue that this can be seen in practice through a comparison of the disparate impact of the virus in different countries. We suggest three broad factors which may account for much of this difference: the presence of scientifically informed leadership with respect for slow science and methodological rigor; societal trust in both science and in political and public health leadership; and a lower degree of income and wealth inequality. The RtS, as elucidated in the Committee on Economic, Social, and Cultural Rights' authoritative General Comment No. 25 (2020), ${ }^{16}$ which in turn relies on relevant provisions of the 2017 UNESCO Statement on Science and Scientific Researchers, ${ }^{17}$ and elsewhere in this volume, provides useful and workable guidance as to how the development of these factors can be encouraged. Rights General Comment No. 25 (2020) on science and economic, social and cultural rights (article 15 (1) (b), (2), (3) and (4) of the International Covenant on Economic, Social and Cultural Rights). https://undocs.org/E/C.12/GC/25.

17 UNESCO General Conference, Recommendation on Science and Scientific Researchers, UNESCO Doc $39 \mathrm{C} / \operatorname{Res} 85$. 
10.2 SOCIETIES AND SCIENCE: THE GOOD, THE BAD, AND THE UGLY

In Blueprint: The Evolutionary Origins of a Good Society, ${ }^{18}$ Nicholas M. Christakis has collected rich evidence from various disciplines to show that historically, whole scientific fields have focused on the dark side of our biological heritage. "In other words, we humans can be awful - prone to selfishness, tribalism, hatred, and violence," writes Christakis. "But, equally, we are good, prone to love, friendship, cooperation, and teaching ... we evolved these capacities, and the good must necessarily have outweighed the bad, in order for us to live as a social species." ${ }^{19}$ It is therefore important not to forget the "human" in "human rights."

"Because [science] is a discipline given to objective fact-finding addressed by hypotheses and using inductive methodologies, it appears by its reliance on empiricism to exclude all consideration of value-laden issues," wrote Richard Pierre Claude, one of the first and foremost commentators on the right to science. "Whether this view stands up to scrutiny or not, it remains obvious that science is a discipline pursued by human beings." ${ }^{20}$ One implication is that the mixed traits Christakis identifies as hallmarks of the human experience - selfishness and tribalism, but also cooperation, teaching and friendship - may influence the motivation and conduct of scientists and through their actions eventually shape the content, quality, and focus of scientific debate and progress.

In the second part of this chapter, we suggest this dynamic is visible in the context of scholarship on the SARS-CoV-2 pandemic. The desire to produce helpful and useful science, which falls squarely within the "good" part of human nature, motivates meticulous adherence to procedures and protocols designed to maximize scientific validity and minimizes any possibility of harm. Science carried out in this way may be termed "slow" science. The desire to help those who are suffering now may tempt less scrupulous scientists to rush publication and cut methodological corners, however. Likewise, the prospect of honor, fame and professional recognition that follow major breakthroughs, perhaps combined with a fear of being scooped, may subconsciously influence even the most methodical and meticulous scientists, editors, and commentators. Where these kinds of motivations significantly influence methodology, we might speak of "fast" science.

The choice or balance between fast and slow science has serious consequences for the fulfillment of the human right to enjoy the benefits of scientific progress and its applications. Indeed, much of the normative content of the right to science aims at

18 N. A. Christakis. Blueprint: The Evolutionary Origins of a Good Society. Little Brown Spark, March, 2019 .

19 N. A. Christakis. Hope in a time of Trump and turbulent campus politics: Interview with Nicholas Christakis. US Today. Mastio, D. USA TODAY Updated 3:05 AM EST Dec 16, 2019. Available at: https://eu.usatoday.com/story/opinion/2019/o4/12/interview-nicholas-a-christakis-blueprint-evolution ary-origins-good-society-column/3425958002/.

2० J. P. Claude. Science in the Service of Human Rights. Philadelphia: University of Pennsylvania Press, 2002,15 . 
preventing the kinds of extraneous influences on scientific method, which characterize fast science. The following section sets the stage for the analysis of fast and slow science by exploring the elements of the right to science in the context of ongoing efforts to combat the SARS-CoV-2 virus. It begins by examining several positive factors, including the high degree of international scientific cooperation, medical altruism, and funding available for scientific research, which represent the "good" in human nature and scientific conduct. In contrast, the disproportionate impact of the pandemic on the already disadvantaged, as well as the evidence of disparate treatment and outright racial discrimination, demonstrate the reality of "bad" factors. Finally, the worldwide reliance on data for scientific progress in general, and on location and contact tracing for COVID-19 positive individuals in particular, renders data science particularly susceptible to dual-use concerns. Where these concerns are warranted, the likely negative impacts are so widespread and so invasive that we may speak of truly repugnant or "ugly" effects.

\subsection{THE GOOD: SCIENCE AS A PUBLIC GOOD}

Human rights, and in particular the right to science, are not only a fundamental human value and a normative imperative for good society. As recognized in paragraph 8 of the CESCR's General Comment No. 25, the benefits of science extend beyond the "material results of the applications of scientific research" to include "the scientific knowledge and information directly deriving from scientific activity" as well as "science's role in forming critical and responsible citizens who are able to participate fully in a democratic society." ${ }^{21}$

When integrated into basic societal rules and principles, human rights are strong generators of economic development, social progress, and international cooperation and assistance. We visualize this relationship below using comparative data connecting human rights protection scores and GDP per capita. The countries included in the analysis are G-7 member states plus Russia, Brazil and the country with the lowest relative number of cases and o deaths - the best overall success in controlling the pandemic.

The "good" of state investment in human rights-relevant factors may be exemplified at the level of international governmental aid. The US State Department and USAID are the largest donors globally, providing nearly \$274 million in annual emergency health and humanitarian assistance to countries in need, in addition to funding already provided to multilateral organizations such as the World Health Organization ${ }^{22}$ and UNICEF. ${ }^{23}$

${ }^{21}$ Supra, n. 11, at para. 8 .

22 The USA donates in excess of $\$ 400$ million per year to the WHO, more than any other country in the world. Nevertheless, US President Trump has accused the WHO of failing to properly respond to the disease, suggesting it was too closely allied to China and has threatened the withdrawal of US funding as a consequence.

23 US Department of State. The United States Is Leading the Humanitarian and Health Assistance Response to COVID-19. March 27, 2020. www.state.gov/the-united-states-is-leading-the-humanitarian -and-health-assistance-response-to-covid-19/. 


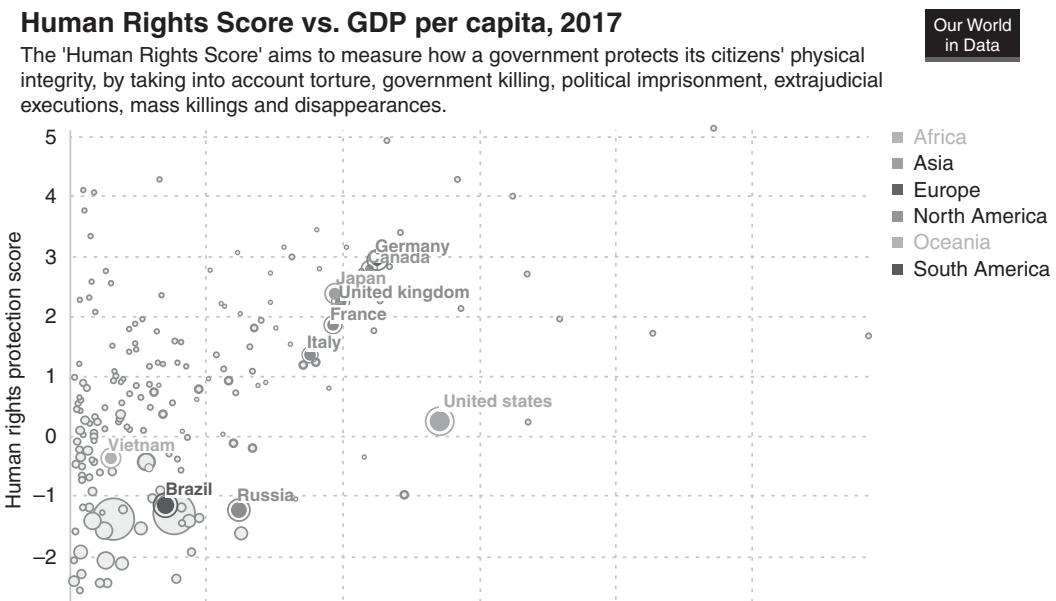

FIgure 10.2 Human Rights Score vs. GDP per capita 1990-2017. "The "Human Rights Score' aims to measure how a government protects its citizens' physical integrity, by taking into account torture, government killing, political imprisonment, extrajudicial executions, mass killings and disappearances". Sources: World Bank, Schnakenberg and Fariss (2014) Fariss (2019). OurWorldData.org/cascade-or-rights/

In the context of the current pandemic, there are several examples of collaborative and altruistic State behavior. For example, the German university hospital in EssenHolsterhausen has admitted COVID-19 patients from France; Albania has issued a group of thirty doctors and nurses to neighboring Italy; and France has responded forcefully to the need for more blood donations. The Chinese corporation Alibaba has donated 500,000 test kits and one million face masks to the US, and several Japanese clothing manufacturers and retailers have donated another million protective face masks to American hospitals. ${ }^{24}$

24 Human Rights Watch. COVID-19: A Human Rights Checklist April 14, 2020. "In Portugal, the government has announced that it will treat people with pending residency and asylum applications as if they were permanent residents until June 30, giving them equal access to health care under the national system. The Italian government extended until mid-June all existing residency permits due to expire, giving those people access to national health care. While the US has made testing for COVID19 free, millions of people in the US are uninsured and unable to get state-funded health care, and medical treatment for the virus still costs more than many people - even those with health insurance - can afford, which forces them to choose between seeking care or risking bankruptcy". Positive examples or transnational intergovernmental collaboration include many governments or international organizations such as the "USA government, Government of Canada, the European Union, the World Bank, and the African Development Bank approved emergency funding for humanitarian assistance to support developing countries' response to COVID-19. Russia provided some medical supplies to the US at below-market cost. The Chinese government has been distributing testing supplies globally, although some recipients have been forced to recall defective tests and masks. Several multinational companies have announced aid efforts." 
Such examples of altruistic and collaborative behavior cannot erase the fact, however, that most of the benefits of scientific progress and its applications are unequally distributed. As scientific knowledge has become a crucial factor in the production of wealth, its international distribution has become steadily more inequitable. This is due to structural asymmetries among countries, regions and social groups, and between races and the sexes. What distinguishes poor people or underdeveloped countries from their richer counterparts is not only that they control fewer assets, but also that they do not create, shape, and enjoy as many benefits of scientific knowledge. ${ }^{25}$

This reality demonstrates the importance of international cooperation, an essential element of the right to science. Article 15(4) ICESCR states that, "[t]he States Parties to the present Covenant recognize the benefits to be derived from the encouragement and development of international contacts and co-operation in the scientific and cultural fields". ${ }^{26}$ Moreover, it illustrates importance of scientific freedom, another essential element recognized in Article 15(3). Without scientific freedom, the safe exchange of medical personnel, technological equipment, and scientific knowledge cannot be guaranteed.

Several steps have already been taken to curb the Coronavirus pandemic. These involve controlling and changing human behavior; searching for drugs and testing vaccines; stimulating the economy; and creating datasets and collecting information from sources as diverse as those about population genetic and public health, traffic controls, and GPS signals, social media sites, purchase transaction records, as well as the climate. In the face of the pandemic, science has been recognized as the strongest and most legitimate instrument to pursue the ideals of a safer life and improved overall human conditions.

This promise of science is, however, conditional on the broad distribution of scientific information and the growth and dissemination of evidence-based knowledge (cf. ICESCR Article 15(2)). ${ }^{27}$ Scientists are expected to search for drug therapies and vaccines and deliver solutions under unprecedented time pressure, potentially undermining these conditions. ${ }^{28}$

\subsection{THE BAD: INEQUALITY AND ACCESS TO SCIENCE}

As the ability to manipulate abstractions and data becomes ever more important for the attainment of societal ends, we should remember that a knowledge society is not

25 World Conference on Science. Science for the 21st Century. Declaration on science and the use of scientific knowledge. www.unesco.org/science/wcs/eng/declaration_e.htm\#top.

26 United Nations Human Rights Office of the High Commissioner. International Covenant on Economic, Social and Cultural Rights. www.ohchr.org/en/professionalinterest/pages/cescr.aspx.

27 Ibid.

28 V. Rul. The most important application of science. EMBO Rep v.15(9); 2014 Sep PMC4198034. 
necessarily a good society. ${ }^{29}$ Neoclassical economic theory equates development with GDP growth that can be measured through the lens of an aggregate production function, relating "relates the total output of an economy to the aggregate amounts of labour, human capital and physical capital in the economy, and some simple measure of the level of technology in the economy as a whole." 30 This model fails to provide an adequate picture even of economic development, as it entirely ignores externalities including, but not limited to, social costs, environmental impacts, and income inequality. ${ }^{31}$

It is not surprising that such an approach to society at times creates fear and reluctance to adopt new technologies. Much of the current inequality both within and between societies can be traced to technical innovations introduced at first to benefit only a privileged minority. ${ }^{32}$ These are partially to blame for the creation of a global society in which, according to a Pew Research Center analysis, the vast majority of the world's population (4.4 billion people $-71 \%$ of the global population of 6.2 billion) lives on a budget that falls well short of the poverty line in advanced economies 33.34 The most recently available data analysis finds that the global middle class encompassed 54 million fewer people in 2020 than the number projected prior to the onset of the pandemic and the number of poor is estimated to have been 131 million higher because of the recession 35 .

Since socioeconomic determinants such as education and poverty are deeply interrelated with health, this stark inequality will be exacerbated as the COVID-19 pandemic plunges the global economy into a synchronized recession the likes of which has not been witnessed since the Great Depression. The rise in the number of people infected by COVID-19 in Africa and South Asia, for example, is creating new economic and social shocks that threaten to deepen global inequalities, especially

29 The Good Society is a journal published by Penn State University press. Articles in the journal respond to the premise that "current versions of socialism and democratic capitalism fail to offer workable visions of a good society and seem increasingly to contradict such basic values as liberty, democracy, equality, and environmental sustainability." The journal publishes outstanding dialectical articles on the pressing political, social, religious, and legal questions facing twenty-first-century society and aims to "create a theoretical basis for the eventual restructuring of real world political-economic systems." Project Muse. The Good Society. Available at: https://muse.jhu.edu/journal/69.

$3^{\circ}$ A. V. Banerjee and E. Duflo. Growth Theory Through the Lens of Development Economics. MIT, March 2004. https://economics.mit.edu/files/798.

${ }^{31}$ R. Costanza, I. Kubiszewski, E. Giovannini, H. Lovins, J. McGlade, K. E. Pickett. Time to leave GDP behind. Nature. 2014; 505: 283-285.

32 The Role of Science and Technology in Society and Governance Toward a New Contract between Science and Society. Executive Summary of the Report of the North American Meeting held in advance of the World Conference on Science. www.nature.com/wcs/mo5s.html.

33 R. Kochhar. Seven-in-ten people globally live on $\$ 10$ or less per day. Pew Research Center. https:// www.pewresearch.org/fact-tank/2015/og/23/seven-in-ten-people-globally-live-on-10-or-less-per-day/

34 M. Roser and E. Ortiz-Ospina. Global Extreme Poverty. The World Bank. March 2017. https:// ourworldindata.org/extreme-poverty.

35 R. Kochhar. The Pandemic Stalls Growth in the Global Middle Class, Pushes Poverty Up Sharply. Pew Research Center. https://www.pewresearch.org/global/2021/03/18/the-pandemic-stalls-growth-inthe-global-middle-class-pushes-poverty-up-sharply/ 
affecting the people living in rural areas or overcrowded megalopolises lacking access to basic health and social services. ${ }^{36}$

Where the obligations imposed on States under the right to science have been met, societies are better prepared for the type of emergency responses necessary in a global pandemic, including effective means of tracing, testing, and quarantining. Article 2 ICESCR provides that

States Parties must take steps, to the maximum of their available resources, for the full realization of the [right to science]. While full realization of the right may be achieved progressively, steps towards it must be taken immediately or within a reasonably short period of time. Such steps should be deliberate, concrete and targeted, using all appropriate means, including the adoption of legislative and budgetary measures. ${ }^{37}$

Moreover, "maximum available resources" $3^{8}$ should be understood to include resources available through international cooperation. Where countries have not met this standard despite good faith attempts to comply with their duty of progressive realization for reasons of resource scarcity, it is frequently the international community's failure to live up to their own obligations which is to blame.

Over the course of the last two decades, developmental economists have attempted to build alternative growth models responsive to the fact that some people are more favored by their legislators and governments than others are. Adherents of the "Unified Growth Theory," for example, have expounded important theoretical perspectives and breakthroughs by studying the interplay between growth and political ${ }^{39}$ as well as social institutions. ${ }^{40}$ The new conception of economy envisaged is a global view of systems of production that have fundamental implications for our everyday material and mental reality. ${ }^{41}$ Unified Growth Theory was designed to resolve the conflict between growth designed to satisfy the interests of profit and the interests of the majority of the population. ${ }^{42}$

P. Akiwumi and G. Valensisi. When it rains it pours: COVID-19 exacerbates poverty risks in the poorest countries. Division for Africa and Least Developed Countries, UNCTAD. May 4, 2020. Supra n. 21.

$3^{8}$ Ibid

39 D. Acemoglu, S. Johnson, and J. Robinson. The colonial origins of comparative development: An empirical investigation. American Economic Review. 2001; 91(5): 1369-1401.

$4^{\circ}$ G. Oded and J. Zeira. Income distribution and macroeconomics. Review of Economic Studies.1993; 6o(1): $35-52$.

${ }^{41} \quad$ I. Tuomi. From Periphery to Center: Emerging Research Topics on Knowledge Society. Technology Review.2001; 116. http://staff.stir.ac.uk/w.m.thompson/Innocom/Library/Knowledge_Society.pdf.

42 G. Oded. From Stagnation to Growth: Unified Growth Theory. Journal Handbook of Economic Growth. 2005; 171-293. 


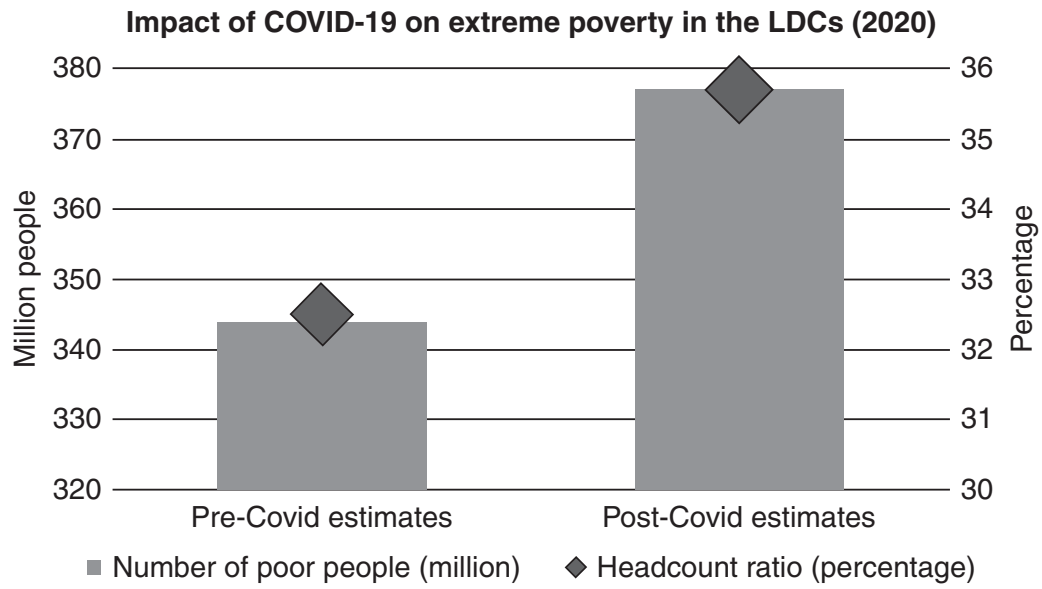

FIGURE 10.3 The worsening economic outlook following the emergence of COVID-19 entails an increase of over three percentage points in LDC poverty headcount, with more than 33 million additional people living in extreme poverty. Source: https://unctad.org /en/pages/newsdetails.aspx?OriginalVersionID $=2356$

\subsection{THE BAD II: DISCRIMINATION}

Human Rights Watch has identified forty questions to guide a rightsrespecting response to the COVID-19 crisis. These principally target the needs of groups most at risk, including people living as ethnic minorities and/or refugees, religious groups, elderly and disabled people, ${ }^{43}$ children and women, and members of the LGTBQ+ community. ${ }^{44}$ Racially discriminatory treatments related to the COVID-19 pandemic have occurred repeatedly around the world. There have been reports of discrimination in employment and housing directed at Africans and people of African descent throughout China, and attempts were made to forcibly test Africans in the Guangdong province. ${ }^{45}$ A significant increase of racist incidents against Asian Australians has been recorded in Australia, ranging from racial slurs to physical assault

43 S. Orešković . No country for old men: five prevalent stereotypes affecting the life of the elderly. Croat Med J. 2020; 61: 184-188.

44 Human Rights Watch. COVID-19: A Human Rights Checklist April 14, 2020. Government officials in many countries "have exhibited disturbing denialism about COVID-19, depriving their publics of accurate information on the pandemic. In India, authorities have done little to curb the spread of viral disinformation which claims that the minority Muslim community is deliberately spreading COVID19. In contrast, United Kingdom police launched investigation into efforts to smear Muslims in UK. In China, outrage over the reprimand of a whistleblower led to a rare apology from the local police". www.hrw.org/news/2020/04/14/covid-19-human-rights-checklist.

45 Human Rights Watch. China: Covid-19 Discrimination Against Africans Forced Quarantines, Evictions, Refused Services in Guangzhou May 5, 2020 12:00AM EDT. www.hrw.org/news/2020/05/ 05/china-covid-19-discrimination-against-africans. 
committed against women (62 percent). ${ }^{46}$ Racial discrimination also plays a part in the pattern of victim-blaming that occurs when inequality widens for communities of color. An exclusive focus on individuals' risky behavior is typically adopted, trivializing the importance of socioeconomic determinants of health in the interpretation of the high mortality rates among people of color.

Analysis of the death toll of COVID-19 furthermore reveals that the poor, uninsured, and members of minority groups are the most affected. The rate of COVID19-related deaths among Black and Latino residents of Chicago and New York is more than twice the Caucasians rate. Similar highly disproportionate rates are measured in other densely populated cities and neighborhoods in the USA. ${ }^{47}$ The need to take public transportation to get to work and/or the presence of pre-existing health problems radically increase exposure to the virus and are necessarily related to socioeconomic status. This is not specific to the USA. In the United Kingdom, black males are 4.2 times and black females 4.3 times more likely to die from a COVID-19-related death than Caucasians. ${ }^{4}$

These disproportionate burdens on already marginalized groups are a particularly egregious violation of the basic human rights principles which underlie the right to science. Unlike the duty of progressive realization, which applies to most obligations derived from this right, there are no excuses under international human rights law for allowing such discrimination to happen. Article 2(2) ICESCR is clear on this point: "The States Parties to the present Covenant undertake to guarantee that the rights enunciated in the present Covenant will be exercised without discrimination of any kind as to race, colour, sex, language, religion, political or other opinion, national or social origin, property, birth or other status."49 The CESCR's General Comment No. 25 reminds us that "States Parties are under an immediate obligation to eliminate all forms of discrimination against individuals and groups in their enjoyment of ESCRs." 50 The obligation to remedy discrimination is absolute, cannot be limited, and obtains even in emergencies and situations involving the total destitution of the State.

One implication is that States Parties must address socioeconomic determinants of exposure. This can happen, for example, by establishing temporary, less crowded

$4^{6}$ N. Zhou. Survey of Covid-19 racism against Asian Australians records 178 incidents in two weeks. The Guardian. Apr. 17, 2020 07:35 BST. Last modified on Apr. 17, 2020 07:36 BST. www.theguardian.com/ world/2020/apr/17/survey-of-covid-19-racism-against-asian-australians-records-178-incidents-in-twoweeks.

47 R. Elving. What Coronavirus Exposes About America's Political Divide. NPR. April 12, 2020, 7:00 AM ET.

$4^{8}$ UK Office of National Statistics. Coronavirus (COVID-19) related deaths by ethnic group, England and Wales: 2 March 2020 to 10 April 2020. www.ons.gov.uk/peoplepopulationandcommunity/birth sdeathsandmarriages/deaths/articles/coronavirusrelateddeathsbyethnicgroupenglandandwales/ 2march2020to1oaprilzozo.

49 Supra n. 21.

50 Supra n. 11, at para. 25. 
institutions (care homes, prisons, schools) or by providing financial incentives not to commute using public transportation (i.e. furlough programs and programs enabling those most in need to stay at home altogether without losing their jobs by subsiding their employers). States could disseminate evidence-based advice on social distancing, hygiene and personal protective equipment, especially among those most in need and least able to otherwise obtain it.

\subsection{THE UGLY: DUAL USE, HARM, CORONAVIRUS CAPITALISM, AND THE DIGNITY OF THE INDIVIDUAL}

A major menace to scientific freedom arises from the interaction between digital technologies and capitalism - specifically, the threat of "surveillance capitalism." 51 This mutant strain of capitalism works by providing free services to citizens in exchange for their personal data, enabling services providers to monitor users' online behaviour with or without their explicit consent.

Although some of these data are applied to service improvement, the rest are declared as a proprietary behavioural surplus, fed into advanced manufacturing processes known as "machine intelligence," and fabricated into prediction products that anticipate what you will do now, soon, and later. Finally, these prediction products are traded in a new kind of marketplace that I call behavioural futures markets. Surveillance capitalists have grown immensely wealthy from these trading operations, for many companies are willing to lay bets on our future behavior. ${ }^{52}$

Why has surveillance capitalism been so successful over the last decade or so? In part, it is because we have lost support from our real-world institutions:

whether it's health care, the educational system, the bank ... It's just a tale of woe wherever you go. The economic and political institutions right now leave us feeling so frustrated. We've all been driven in this way toward the internet, toward these services, because we need help. And no one else is helping us. That's how we got hooked. ${ }^{53}$

Coronavirus Capitalism is an even newer term coined to cover a broader set of structural changes resulting from the pandemic.54 The analogy of "surveillance capitalism" is applicable to the role of digital technologies in the context of the COVID-19 pandemic: technologies employed by governments around the world are aimed at identifying how infected people behave, where they move, with whom they

${ }^{51}$ Zuboff, Shoshana. The Age of Surveillance Capitalism: The Fight for a Human Future at the New Frontier of Power. London, England: Profile Books. 2019.

52 Ibid.

53 S. Zuboff. A fundamentally illegitimate choice. Sam Biddle, The Intercept. February 2, 2019. https:// theintercept.com/2019/oz/oz/shoshana-zuboff-age-of-surveillance-capitalism/.

54 N. Taplin. Coronavirus Capitalism Has a Darker Side. Wall Street Journal. April 9, 2020 6:50 am ET. www.wsj.com/articles/coronavirus-capitalism-has-a-darker-side-11586429401. 
socialize, but not only for the purpose of monitoring self-isolation or enforcing quarantines. Governments are demanding extraordinary new surveillance powers ${ }^{55}$ intended to contain the virus' spread.

Significant problems related to data security may arise from private corporations storing large quantities of consumers' personal data. Instead of looking to invest their resources in boosting testing, unchecked power-seeking governments might end up using the COVID-19 surveillance technologies to normalize data gathering on individuals for the purpose of social and political control. ${ }^{56}$ This prospect would not comply with the European Data Protection Board (EDPB)'s guidelines, which state that restrictions of freedom during the pandemic are acceptable only to the extent that they are consistent with narrowly defined purposes, limited timeframes, and the recommendation that "pseudonymisation, encryption, non-disclosure agreements and strict access role distribution, access role restrictions as well as access logs should be employed." 57

For example, machine-readable QR codes, which are typically used to store URLs or other information to be scanned by smartphone cameras, have been used to monitor citizens and alert authorities about the movements and actions of individuals who have tested positive for SARS-CoV-2 in China, Russia, and Hong Kong. Closed-circuit television has been deployed to track such individuals in South Korea. In Israel, citizens' cell phone location data are used for quarantine control purposes by the government $\mathrm{t}^{5}$.

The EU currently proposes to track citizens using Bluetooth. Computer science and machine learning experts from eight European nations are developing the PanEuropean Privacy-Preserving Proximity Tracing Project, 59 which aims to enable technologies to alert users to the presence of nearby individuals who have tested positive for the virus. Moreover, the Massachusetts Institute of Technology is

55 Human Rights Watch reports that "China, Iran, and Russia are using digital surveillance measures that threaten individuals' right to privacy, free expression, and association. Armenia and Israel passed sweeping laws that threaten privacy by requiring telecommunications companies to turn over phone call histories and location data to authorities. In South Korea, new regulations allow authorities to send anonymized information about individuals' movements to the general public, but the updates have included enough detail that they left people wary of their private lives being exposed. While data protection guarantees vary in each context, France, Germany, India, Italy, Poland, Singapore, the UK, and the US are also exploring or already using cell phone location data or facial recognition." www.hrw.org/news/2020/04/14/covid-19-human-rights-checklist.

${ }^{6}$ S. Cunningham. Privacy nightmare or potential salvation? The new pan-European platform that aims to disrupt COVID-19 transmission chains. KCRW. Berlin. https:/kcrwberlin.com/2020/o4/privacynightmare-or-potential-salvation-the-new-pan-european-platform-that-aims-to-disrupt-covid-19-trans mission-chains/.

57 EDPB. Guidelines $03 / 2020$ on the processing of data concerning health for the purpose of scientific research in the context of the COVID-19 outbreak. April 21, 2020. https://edpb.europa.eu/our-worktools/our-documents/guidelines/guidelines-032020-processing-data-concerning-health-purpose_en.

$5^{8}$ RS Surber. Corona pan(dem)ic: gateway to global surveillance. Ethics Inf Technol. 2020;1-10. doi:10.1007/s10676-020-09569-5

59 Pan-European Privacy-Preserving Proximity Tracing. (PEPP-PT). www.pepp-pt.org/. 
developing new platforms using existing mobile technologies to enable privacypreserving contact tracing. The aim of these platforms is to enable health care providers to download the names of those who have been physically close to infected individuals. Algorithms developed by data scientists will furthermore be able to integrate data from different sources to forecast precise community-level infection risks. ${ }^{60}$ All these examples are the result of the theory that the interest of public health prevails over privacy rights and interests when the demand for processing sensitive private information increases due to severe threats ${ }^{61}$ to survival among the general population.

The Joint Civil Society Statement, issued by more than one hundred national and international civil society organizations, "urge[s] governments to show leadership in tackling the pandemic in a way that ensures that the use of digital technologies to track and monitor individuals and populations are carried out strictly in line with human rights." ${ }^{62}$ Proposals that would invade privacy, deter free speech, and disparately burden vulnerable groups are not acceptable, the Electronic Frontier Foundation argues, and suggests three questions to be answered in every situation when decisions are being made to give greater surveillance powers to the government:

1) Would the proposal work?

2) Would it excessively intrude on privacy and freedoms?

3) Are there sufficient safeguards? ${ }^{63}$

These misgivings show that the kind of surveillance characterizing Coronavirus Capitalism is liable to misuse. The problem is familiar from pre-Corona contexts, but the emergency powers sought by governments to combat COVID-19 are more extensive and invasive. The problem arises from the fact that the same technologies - surveillance,

6o J. Shah and N. Shah. Fighting Coronavirus with Big Data. Harvard Business Review. April o6, 2020. https:/hbr.org/2020/o4/fighting-coronavirus-with-big-data.

61 A. Kharpal. Use of surveillance to fight coronavirus raises concerns about government power after pandemic ends. March 30, 2020,12:17 PM EDT. www.cnbc.com/2020/03/27/coronavirus-surveillanceused-by-governments-to-fight-pandemic-privacy-concerns.html.

62 The Joint Civil Society Statement addresses the surveillance measures adopted to fight the pandemic. The Statement insists that "it must be lawful, necessary and proportionate, should only continue for as long as necessary to address the current pandemic, increased collection, retention, and aggregation of personal data, including health data, is only used for the purposes of responding to the COVID-19 pandemic, any claims that data is anonymous must be based on evidence how it has been anonymized. Surveillance should not facilitate discrimination against racial minorities, people living in poverty, and other marginalized populations., Data sharing agreements with other public or private sector entities must be based on law and publicly disclosed, should not fall under the domain of security or intelligence agencies, and should include means for free, active, and meaningful participation of relevant stakeholders, in particular experts in the public health sector and the most marginalized population groups." Human Rights Watch. Joint Civil Society Statement: States use of digital surveillance technologies to fight pandemic must respect human rights. www.hrw.org/news/ 2020/04/o2/joint-civil-society-statement-states-use-digital-surveillance-technologies-fight.

$6_{3}$ Electronic Frontier Foundation. COVID-19 and digital rights. www.eff.org/issues/covid-19. 
tracking and tracing, identification, and contact using ICTs - which are capable of producing vast benefits (as the case of successful contact tracing in South Korea shows) are also capable of producing great harm through bad faith, selfish or even hostile uses. In the case of invasive individual surveillance, it is not hard to see that a wealth of information concerning individuals may be connected, amassed and analyzed. Nor is it difficult to appreciate that much of this information is likely to be sensitive and may give rise to neglect, discrimination, or even persecution, for data subjects, as well as unjust enrichment and undemocratic influence for those who wield the power of the resulting knowledge. Given the sheer scale of data involved, and the ease with which systems meant for emergencies may be repurposed for continued use, the danger of dual use may well be one of the ugliest problems currently facing societies.

The problem of dual-use surveillance also raises the issue of respect for human dignity. Dignity has a special meaning in international human rights law, where it serves as the foundational value from which human rights are derived. ${ }^{64}$ Although a detailed definition is outside the scope of this chapter, dignity may be said to involve respect for individual autonomy and desires, balanced against interference with those of others, and entitlement to acknowledgement and respect as an agent whose life and interests have inherent value. Thus, dignity is violated whenever individuals are treated merely as tools or objects for the achievement of some purpose. Such treatment respects neither the equal rights of all humans nor their cognitive and affective capacities. The constellation of nonconsensual and exploitative practices which make up Coronavirus Capitalism not only undermine the interests of individuals to maintain the privacy necessary for self-development and the cultivation of relationships; they also fail to offer a reasonable degree of informational freedom.

\subsection{THE UGLY II: EXECUTIVE DISTRUST OF SCIENCE}

Not every country has reacted in the same manner during the pandemic, with the same level of ethical, social, and scientific responsibility, transparency, and evidence-based policies. Indeed, there are already indicators of significant differences in the transfer of knowledge and use of evidence-based policy between the highly developed EU countries as well as the USA. Whether members of high-risk groups, such as the elderly and people with preconditions, will live or die depends on the response of world leaders to the idea of evidence-based policy and the right to enjoy the benefits of scientific progress. Politics of denial and limited public access to evidence-based information and

64 On dignity in ethics and human rights see Andorno, Roberto. "Human Dignity and Human Rights as a Common Ground for a Global Bioethics" (2009). Journal of Medicine and Philosophy, Vol. 34, Issue 3, pp. 223-240 and Porsdam Mann, S., Sun, R. and Hermerén, G. "A framework for the ethical assessment of chimeric animal research using human neural tissue" BMC medical ethics 20 (1), 1-9. https://doi.org/10.1186/s12910-019-0345-2. 
independent scientific sources on the virus's spread have already contributed to the loss of hundreds of thousands of lives. In some countries, responses from heads of state have been marked by distrust of science, cover-ups, and ad hominem attacks on doctors who sounded the alarm at the beginning of the outbreak. There have been "predictions" that the virus would disappear like a miracle one day and dismissals of the disease as a hoax fantasy and a little flu. ${ }^{65}$ Manipulation, exaggeration and conspiracy theories on the origins of SARS-Cov-2 are rampant, spreading faster than the virus and likewise producing deadly effects. Some of the most widespread are that:

- The virus has escaped from a Chinese laboratory in Wuhan

- The US military brought the virus to Wuhan

- ${ }_{5} \mathrm{G}$ networks spread the virus

- The virus was created by Bill Gates who wants to make billions on the vaccine.

Social scientists are trying to chart the path of disinformation in the same way that epidemiologists are tracking the transmission of a new virus, with a special focus on so-called "superspreaders" whose actions cause significantly more viral dissemination than others. ${ }^{66}$ Some politicians have held political rallies, kissing supporters and promoting an aversion to scientific inquiry and public health institutions. One aspect of populist manipulation of reports and official figures, which has puzzled researchers, is the reported mortality rate in many countries being far below those measured, expected, or projected for comparable economies, societies or health care systems. For example, Russia is positioned in upper tier of the Europe region in terms of number tests per million population ( 830926 tests / 1 million people - 121 300000 tests in total while Denmark leads the way with 4476378 tests / 1 million people - 25996859 tests in total) However, Russia is standing, as of this writing, at 4,5 million reported cases and 99.000 deaths, resulting in relatively low 31,258 cases per million, ${ }^{67}$ and even lower level of deaths per million if compared to most of G-8 average, (Russia reports 683 deaths per million compared to UK reporting 1861 deaths per million, Italy, 1827 , USA 1705 , Germany 921$)^{68}$. This is a country with an underfunded and vertically disconnected health care system, and in which no satisfactory explanations for such superior performance are obvious.

Z. Rasheed. COVID-19 pandemic is testing world leaders. Who's stepping up? www.aljazeera.com /news/2020/04/covid-19-pandemic-testing-world-leaders-stepping-200402201221844.html.

66 P. Ball and A. Maxel. The Epic Battle Against Coronavirus Misinformationa and Conspiracy Theories. Nature, May 27, 2020. www.nature.com/articles/d41586-020-01452-z.

${ }^{6} 7$ For example, The New York Times reports that a senior WHO official found Russia's figures "suspicious" on May 11, 2020. I. Necheporenko. "A Cornoravirus Mystery Explained: Moscov Has 1,700 Extra Deaths.” New York Times, May 11, 2020. www.nytimes.com/2020/05/11/world/europe/ coronavirus-deaths-moscow.html.

68 Worldometer. Reported Cases and Deaths by Country or Territory. https://www.worldometers.info /coronavirus/?utm_campaign=homeAdvegası?\%20 
Though fairly common, national responses aimed at obscuring the true extent of the virus's impact, constitute clear and fundamental violations of no less than three of the core minimal obligations of the right to science. The CESCR explicitly provides, in paragraph 52 of its General Comment No. 25, that the following obligations are "core," such that no government may be excused for failing to fulfil them unless they demonstrate exhaustion of available domestic and international resources in bona fide attempts at fulfillment (paragraph 51).

Core obligations related to the [right to science] require States, inter alia, to:

Adopt mechanisms aimed at aligning government policies and programs to the best available, generally accepted scientific evidence;

Adopt mechanisms to protect people from the harmful consequences of false, misleading and pseudoscience-based practices, especially when other ESCRs are at risk;

Promote accurate scientific information and refrain from disinformation, disparagement, or deliberate misinforming of the public, so as to erode citizen understanding and respect for science and scientific research. ${ }^{69}$

\subsection{SCIENCE: FAST AND SLOW}

Unfortunately, a rigorous approach to scientific method is a slow and ponderous process. Trials must adhere to strict safety and statistical standards. They have to obtain ethical review. Their results need to be confirmed by other trials and discussed in open scientific fora. Before they can be published, they typically undergo peer review. As a result, the scientific process operates on a temporal resolution of years and decades. Yet the Coronavirus cannot be persuaded to wait, and thousands need a cure, vaccine or treatment now. As a result, the natural, social and behavioral sciences are all under great pressure to answer difficult questions quickly. Whether consciously or subconsciously, methodological niceties and research credibility may be sacrificed or neglected in the process, leaving research or policy papers open to criticism.

A good example is the statistical bias which arises from attempts to understand the share of people who have contracted the coronavirus. Basic but fatal problems arise from the misinterpretation and miscalculation of epidemiological concepts. The second most important cause of bias is that a key metric, the number of deaths caused by coronaviruses, tends to lag. Although many regions publish daily death counts, these are typically underestimates and suffer from unrepresentative sampling and daily variability. The sampling-variability issue is exacerbated by the fact that polls or studies with extreme results are more likely to get reported on ("publication bias"). ${ }^{70}$

69 Supra n. 21.

70 D. Kopf. Three concepts for interpreting data in the age of coronavirus. The Quartz. April 25, 2020. 
Consequently, we cannot rely completely on the data that partly inform the $500+$ research papers on COVID-19 published daily. The primary cause for this explosion in publications is the adoption of new scientific practices, stimulating scientists to share pre-print research directly online, without formal peer-review. These new practices have engendered a fair amount of skepticism. Like fast food, hastily compiled junk science ${ }^{71}$ can be deleterious for health. Conflicts and mixed messages among scientists are symptomatic of a rushed approach and have stymied efforts to tackle the most pressing issues. ${ }^{72}$

The scientific knowledge and individual and collective experience we are amassing over the course of the SARS-CoV-2 pandemic will be the basis for the knowledge of tomorrow. Ideally, this knowledge and experience will inform the creation of new tools and techniques which in turn will help us collectively control future epidemics. Some will argue that the conduct of the scientific process - from generating hypotheses to designing research and evaluating hypotheses - should be a valueneutral exercise. However, conducting science in accordance with the requirements of the eponymous right means engaging with the concerns of the public, rather than shutting these out. In the words of Isabelle Stengers, scientists ought to behave like the

"thinking, rational brain of humanity" and refuse to allow their expertise to be used to shut down the concerns of the public, or conversely, to spread the belief that scientific progress is inevitable and will resolve all of society's problems. Rather, science must engage openly and honestly with an intelligent public and be clear about the kind of knowledge it is capable of producing. ${ }^{73}$

The sometimes completely unrealistic societal expectations from science and technologies are vividly illustrated by the current pandemic. ${ }^{74}$ The biomedical research pipeline begins with rigorous safety checks on small experimental groups during Phase 1; expands to groups of a few hundred in Phase 2; thousands in Phase 3; and only then may Phase 4 trials be initiated. Months normally pass between phases so that researchers can review the findings and obtain approval to proceed to subsequent phases; the process of bringing novel pharmaceuticals can thus extend over

${ }^{71}$ See bioRxiv. When citations come before peer-review - A new normal. 12 preprints on COVID-19 that have been supported or contradicted by subsequent research. https://medium.com/scite/12-preprintson-covid-19-that-have-been-supported-or-contradicted-by-subsequent-research-2ef1738eoraz.

72 The Slow Science Academy in Berlin has stood against such tendencies since its 2010 publication of a slow-science manifesto: "Slow science was pretty much the only science conceivable for hundreds of years; today, we argue, it deserves revival and needs protection. Society should give scientists the time they need, but more importantly, scientists must take their time. We do need time to think. We do need time to digest. We do need time to misunderstand each other, especially when fostering lost dialogue between humanities and natural sciences. We cannot continuously tell you what our science means; what it will be good for; because we simply don't know yet. Science needs time." Available at: http://slow-science.org/.

73 I. Stengers. Another Science is Possible: A Manifesto for Slow Science. Polity: 2018.

74 M. Borup, N. Brown, K. Konrad, and H. Van Lente. The sociology of expectations in science and technology. Technology Analysis \& Strategic Management. 2006; 18:3-4: 285-298. 
years or decades. Since 1992, the US Food and Drug Administration's development and drug approval standards and procedures include a track for the accelerated approval of antiretroviral drugs. Originating from the need to enable rapid access to HIV/AIDS medication, the FDA's accelerated approval track can be "applied to promising therapies that treat a serious or life-threatening condition and provide therapeutic benefit over available therapies." 75 The influence of the "fast" process can be illustrated by reference to the incredible statistic that nearly 30,000 of the COVID-19 articles published in 2020 were preprints - between $17 \%$ and $30 \%$ of total COVID-19 research papers Journals rushed to get COVID-19 articles through peer review. MedRxiv COVID-19 preprints appeared in peer-reviewed journals after a median review time of 72 days, twice as fast as preprints from the server on other topics $^{76}$. The US National Library of Medicine's trial registry, ClinicalTrials.gov, presently records 5.248 ongoing or completed COVID-19 studies. The number of studies already recruiting patients is exceptional, at 2562 current studies. ${ }^{77}$ This pace is unprecedented in the history of science and medicine. Nevertheless, both the SARS-CoV-2 virus and the resultant COVID-19 disease are novel biological phenomena. Despite the fact that there only few vaccines for COVID-19 approved by either the $\mathrm{FDA}^{78}$ or the European Medicines Agency (EMA), ${ }^{79}$ unscrupulous companies are attempting to profit from the pandemic through illegally marketed and scientifically untested products falsely claimed to be efficacious against the disease.

A famous example of this phenomenon is hydroxychloroquine, a sometime antimalarial drug publicly promoted by US President Trump ${ }^{80}$. This drug was the subject of two major papers published in The Lancet and New England Journal of Medicine, the premier medical journals of the United Kingdom and US, respectively. The studies were both based on a database purportedly derived from the medical records of 96,000 COVID-19 patients. Their publication "had considerable impact, halting clinical trials of malaria drugs around the world and providing

75 US Food \& Drug Administration. Development \& Approval Process | Drugs. www.fda.gov/drugs/ development-approval-process-drugs.

$7^{6}$ E. Holly. How torrent of COVID science changed research publishing - in seven charts. https://www .nature.com/articles/d41586-020-03564-y

77 US National Library of Medicine. ClinicalTrials.gov. Updated 30 May, 2020. https://clinicaltrials.gov $/$ ctz $/$ results? cond $=$ covid $-19 \&$ term $=\&$ cntry $=U S \&$ state $=\&$ city $=\&$ dist $=\&$ recrs $=$..

$7^{8}$ US Food and Drug Administration. Beware of Fraudulent Coronavirus Tests, Vaccines and Treatments. April 29, 2020. www.fda.gov/consumers/consumer-updates/beware-fraudulentcoronavirus-tests-vaccines-and-treatments.

79 European Medicines Agency. Treatments and Vaccines for COVID-19. www.ema.europa.eu/en/ human-regulatory/overview/public-health-threats/coronavirus-disease-covid-19/treatments-vaccinescovid-19\#potential-treatments-under-investigation-section.

8o A. Solender. All The Times Trump Has Promoted Hydroxychloroquine. Forbes, May 22, 2020. www .forbes.com/sites/andrewsolender/2020/05/22/all-the-times-trump-promoted-hydroxychloroquine /\#2d 336 df64643. 
reassurance about the risks of blood pressure medications taken by millions of

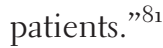

Based on suspicions about the source and accuracy of this database, more than a hundred academics signed an open letter to the editor of The Lancet requesting an independent validation of the study and details of the supporting evidence. ${ }^{82}$ Both studies were subsequently retracted when it emerged that Surgisphere Corporation, the proprietors of the database, had refused access to its full contents to independent reviewers. ${ }^{83}$ Under normal circumstances, the editorial and research standards in these journals is so high that retractions or allegations of serious mistakes or omissions are rare, especially in cases of studies, such as these two, authored by senior professionals from prestigious institutions. They would take months or years to conduct and go through multiple rounds of analysis and review. However, these studies went through the entire research pipeline from data analysis through submission to publication in little over five weeks. To the extent that such a hastily crafted paper would be unlikely to pass editorial and peer review in less pressured times, this story illustrates the impact that the "fast" process can exert, even in the best medical journals.

The difficult history of HIV treatment and the deployment of vaccines against the $\mathrm{H}_{1} \mathrm{~N}_{1}$ outbreak in 2009 illustrate that even when tools have been available, they have not been equally available to all. In the long run, therapeutic drugs, together with vaccines, might change the fight against COVID-19 too. ${ }^{84}$ One potential source of such optimistic and promising vaccine-development is that such "speculations" have caused the stocks of companies developing vaccines to surge and more than double since late February, despite some of these companies having never successfully brought a single product to market. For politicians, it is an attempt to invest in the potential surge of public support ahead of elections. Developing such huge expectations from science may be wreaking potentially serious damage to the

81 R. Rabin. Scientists Question Medical Data Used in Second Coronavirus Study. The New York Times, June 2, 2020. www.nytimes.com/2020/06/o2/health/coronavirus-study.html.

82 "An Open Letter to [the authors] ... and Richard Horten (the Editor of The Lancet." https://zenodo .org/record/3862789\#.Xu.

83 In retracting the study, The Lancet stated that "several concerns were raised with respect to the veracity of the data and analyses conducted by Surgisphere Corporation and its founder and our co-author, Sapan Desai, in our publication... As such, our reviewers were not able to conduct an independent and private peer review and therefore notified us of their withdrawal from the peer-review process. We always aspire to perform our research in accordance with the highest ethical and professional guidelines. We can never forget the responsibility we have as researchers to scrupulously ensure that we rely on data sources that adhere to our high standards. Based on this development, we can no longer vouch for the veracity of the primary data sources. Due to this unfortunate development, the authors request that the paper be retracted." The Lancet. Retraction - Hydroxychloroquine or chloroquine with or without a macrolide for treatment of COVID-19: a multinational registry analysis. www.thelancet.com/journals/lancet/article/PIISor4o-6736(20)31324-6/fulltext.

84 S. A. Thompson. How Long Will a Vaccine Really Take? New York Times. April 30, 2020. www .nytimes.com/interactive/2020/04/30/opinion/coronavirus-covid-vaccine.html. 
reputation and credibility of science as a source of knowledge, directly undermining the principles underlying the right to science.

\subsection{DISCUSSION: THE IMPORTANCE OF TRUST IN SCIENCE AND EVIDENCE AND HOW TO BUILD IT}

The global spread of the SARS-CoV-2 virus and COVID-19 pandemic is an unexpected opportunity to see the principles of the right to science, and the effects of their absence, in action. It is also an opportunity to measure the quality and the pace of the implementation of scientific and applied science recommendations found in the ICESCR, General Comment No. 25, and the 2017 UNESCO Statement on Science and Scientific Researchers, which is the source of several of the normative definitions of terms used by the CESCR in its General Comment.

Figure 10.4 shows that only two countries among the most affected developed countries have experienced relatively positive outcomes of their attempts at prevention and viral control. Japan and Germany were well prepared, highly organized, and exceptionally effective with respect to prevention and tertiary intervention policies. Germany has since led the way in Europe with large-scale testing for COVID-19, collecting more than 50 million samples (6oo per million) since the start of the crisis. Although the country as of the time of writing ranks seventh globally for the number of confirmed cases - exceeding 2.9, million infections (34.144 per million) - the fatality rate is much lower than those of other developed

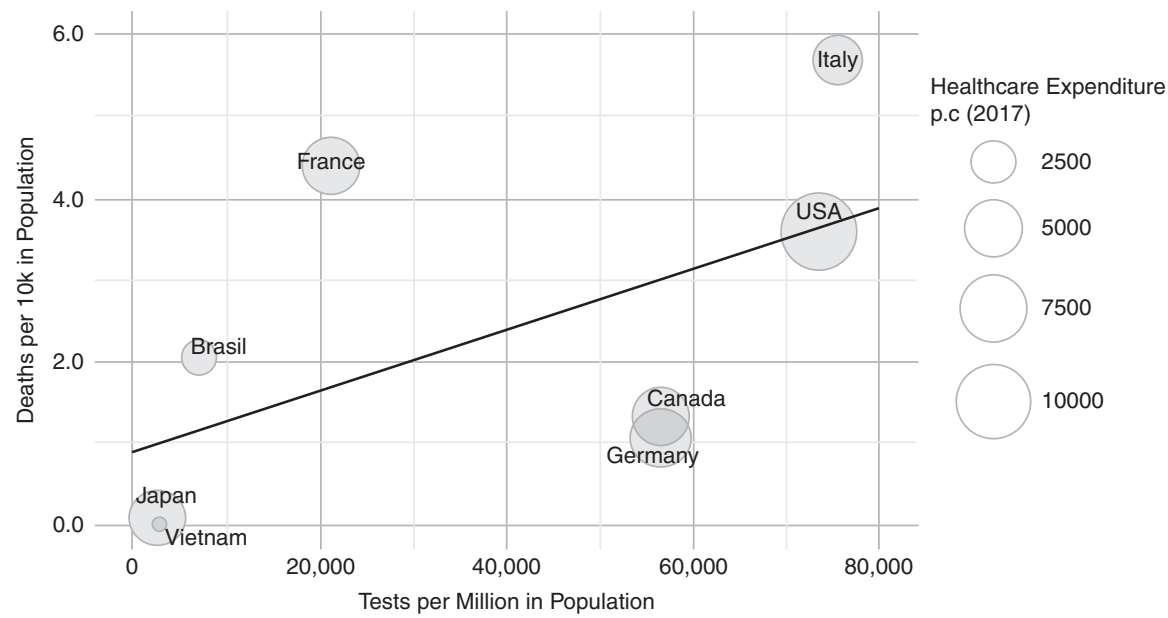

FIGURE 10.4 The relation between rate of deaths, SARS-CoV-2 testing frequency and expenditures on health per capita in the G-8 countries as compared to Vietnam - the most successful country in managing COVID/19 pandemics. Source: author's composite from various databases. 
countries at 921 deaths per million. Japan represents an even more interesting and successful case with close to 500.000 infection cases (3.784 per million) and 9.195 deaths (73 deaths per million) so far recorded.

Among non-Western countries, success stories in handling the novel coronavirus outbreak include only highly developed countries such as South Korea, Taiwan and Hong Kong. However, there is one exception to this rule. Vietnam, a country of 97 million inhabitants, had not reported a single coronavirus-related death by June 9, 2020 and as of that time reported just 2.620 confirmed cases ( 27 per million!) and 0,4 deaths per million (total of 16 deaths!). Vietnam is a low-middle income country (2.185 USD per capita in 2017) with a low-spending healthcare system (130 USD per capita in 2017) and only 8 physicians per 10,000 population. However, unlike the case of Russia, there are several explanatory factors lending credence to Vietnam's claims. Fresh experience with the previous SARS and $\mathrm{H}_{5} \mathrm{~N}_{1}$ epidemics allowed Vietnam to respond with immediacy, effectiveness, and transparency. The country relied on just four solutions, all of them cost-effective, to combat the virus: speedy implementation of a national lockdown; strategic testing (26.519 test per 1 million population $)^{85}$ using WHO-approved techniques and testing only those likely to be infected); contact tracing through apps; and effective public communication campaigns. Vietnam was also the first country in the world to be cleared of the SARS outbreak in 2003.

Based on these experiences, the most important factor influencing effectiveness of overall national policy appears to have been an educated approach to and respect for facts, evidence, and science from the national leadership as well as critical respect for international institutions. ${ }^{86}$

Learning from the scientific evidence and evidence-based practice in study of the effectiveness of non-pharmaceutical interventions against spread of SARS-CoV-2 is an imperative. Control of the pandemic while using combinations of movement restrictions, physical distancing, hygiene practices, and intensive case and contact detection and management proved effective in China, Singapore, and South Korea. However, the New Zealand government's strategy is unique because it represents the most effective strategy in high-income democratic setting, if measured by outcomes, while employing scientific evidence and technical expertise in controlling COVID19 with total of 2501 cases and 25 cumulative deaths (500 cases and 5 deaths per 1 million population).

85 Worldometer. Reported Cases and Deaths by Country or Territory. https://www.worldometers.info /coronavirus/?utm_campaign=homeAdvegast?\%20

86 A video clip which has been shared hundreds of thousands of times on social media shows Merkel's explanation of the scientific basis behind her government's lockdown exit strategy. "She had all the calm confidence expected of a former research scientist with a doctorate in quantum chemistry who once co-authored a paper on the 'influence of spatial correlations on the rate of chemical reactions'." P. Olterman. Angela Merkel draws on science background in Covid-19 explainer. The Guardian. www.theguardian.com/world/202o/apr/16/angela-merkel-draws-on-science-background-in-covid-19explainer-lockdown-exit. 
Technical advisory group appointed by the Ministry of Health developed a strategy comprising of combination of intensive case and contact detection and management, physical distancing, movement restrictions, hygiene practices, and highlighting transmission hotspots and targeting community testing. It has been one of the keys to the success of its SARS-CoV-2 elimination and control strategy. It comprised of the following several science-led ${ }^{87}$ sub-strategies as described in Nature Immunology paper:

- Quick and radical lockdowns. During the first wave of the pandemic (March 2020) the government implemented quick and radical lockdowns including travel restrictions and border closures. The speed and intensity of the New Zealand's governmental response to limit the epidemic is unprecedented internationally ${ }^{88}$ representing the fastest trajectory to reach the highest country score in the Government Response Stringency Index ${ }^{89}$.

- Timely and targeted testing. A key feature of the success in eliminating SARS-CoV -2 was moving early (January 31, 2020) to rapidly develop and implement in-house laboratory RT-PCR (PCR with reverse transcription) tests for SARS-CoV-2. The initiative was developed by regional diagnostic laboratories and academic scientists. Total number of 1.9 million people have been tested (380.000 per million population) significantly lower percentage of population tested as compared to the G-8 countries (UK 1.871.000 per million, USA 1.219.000 per million)

- Viral genomics. Viral genomics was also critical to New Zealand's successful public health response, with genomic sequencing being used as a key tool for understanding and limiting the spread of COVID-19

- Integrating genomics with epidemiological and modeling data. Local transmission chains and regional spread were able to be tracked and audited in real time

- Geographic information. When combined with geographic information, the pathways of viral spread, including from the global population, domestically and at the community level, were more easily revealed

- Superspreading events. A special focus of control was directed to identify superspreading events and trigger focused interventions.

- Transparent and credible governmental policy. Timely and decisive national leadership of New Zealand's by prime minister Jacinda Ardern was evidenceinformed combining, rigorous case detection, isolation, contact tracing, and quarantine measures with population education and engagement.

These are the very qualities which national leaders are obliged to demonstrate, without excuses or qualifications, as a bare minimum to fulfill their duties under

87 J. L. Geoghegan, N. J. Moreland, G. Le Gros, J. E. Ussher. New Zealand's science-led response to the SARS-CoV-2 pandemic. Nat Immunol 22, 262-263 (2021). https://doi.org/10.1038/s41590-021-00872-X S. Jefferies et al. COVID-19 in New Zealand and the impact of the national response: a descriptive epidemiological study. The Lancet Public Health, Volume 5, Issue 11, e612 - e623

89 OXFORD COVID-19 Government Response Stringency index. https://data.humdata.org/dataset/ oxford-covid-19-government-response-tracker 
international human rights law. Thus General Comment No. 25 includes in its list of core minimal obligations (paragraph 52 ) the following:

- Ensure access to those applications of scientific progress that are critical to the enjoyment of the right to health and other ESCRs;

- Foster the development of international contacts and co-operation in the scientific field, without imposing restrictions on the movements of persons, goods and knowledge beyond those which are justifiable in accordance with article 4 of the Covenant.

- Develop a participatory national framework law on the RPEBSPA, which includes legal remedies in case of violations, and adopt and implement a participatory national strategy or an action plan for the realization of the RPEBSPA, which includes a strategy for the conservation, the development and diffusion of science;

- Adopt mechanisms aimed at aligning government policies and programs to the best available, generally accepted scientific evidence;

- Ensure that people have access to basic education and skills necessary for the comprehension and application of scientific knowledge and that scientific education in both public and private schools respect the best available scientific knowledge. ${ }^{90}$

Where individuals are informed and knowledgeable in scientific matters and methods, their trust in results derived from science is greater. Where government officials, and especially national leaders, are informed and knowledgeable, and act in accordance with scientific evidence and human rights, citizen trust in both their leadership and in science itself increases. This is explicitly recognized in paragraph 54 of General Comment No. 25:

A clear benefit of scientific progress is that scientific knowledge is used in decisionmaking and policies, which should, as far as possible, be based on the best available scientific evidence. States should endeavor to align their policies to the best scientific evidence available. They should, furthermore, promote public trust and support for sciences throughout society and a culture of active citizen engagement with science, in particular through a vigorous and informed democratic debate on the production and use of scientific knowledge, and a dialogue between the scientific community and society. ${ }^{91}$

\subsection{CONCLUSION}

Trust in evidence-based policy and the right to science is a significant explanatory factor of the sharp contrast in the figures for deaths per 100,000 persons and case-fatality

90 Supra n. 11, at para. 52 .

$9^{1}$ Ibid., at para. 54 . 
between Japan Japan $(7.25 / 1,9 \%)$, Canada $(62.06 / 2.3 \%)$, Russia $(67,55 / 2,2 \%)^{92}$, Germany $(92.64 / 2.7 \%)$, France $(143.47 / 2.0 \%)$, the US (169.07.11.8\%), Italy (181.87/3.0\%) and the United Kingdom (191,02/2.9\%) respectively attributed to the SARS-CoV-2 virus. ${ }^{93}$. That helps us better understanding the governmental policies and social behavior determining not only the number of number of cumulative cases ${ }^{94}$ but also in some cases capacity to organize effective vaccination policy ${ }^{95}$ The extent of such trust is not only a question of how educated leaders are or how many scientists are directly involved in government or administrations. ${ }^{96}$ It is also a question of the scientific organizational and social experience with epidemics, behavioral habits, cultural values, and respect for the institutional setup within and between nations.

This suggests and illustrates the significance of whether or not policy in general, and scientific policy in particular, follows the facts, data, and guidelines, as well as how much we adhere to the idea of a right to science. Given the general acknowledgement of the necessity and importance of science in the fight against COVID19 , it is an interesting question whether the respect for science generated by the episode is enough to counter the much-maligned pre-pandemic rise of "alternative facts" and "fake news" in the aftermath of the pandemic. Whatever the eventual outcome, the case of the SARS-CoV-2 virus pandemic clearly demonstrates that the right to science is equally challenging to implement and just as important for nations of the world as the idea of science itself. However, this chapter's analysis of the elements of the right to science and their ability to enhance societal trust in science indicate that attempting to meet that challenge is a good idea.

The official figures coming from Russia, as well as from several other countries in EU and developing countries including Mexico, Belarus and India are contradictory.

93 Johns Hopkins University Medicine. COVID-19 Dashboard by the Center for Systemic Science and Engineering (CSSE) at Johns Hopkins University. https://coronavirus.jhu.edu/data/mortality.

94 Johns Hopkins University Medicine. Cumulative cases by days since $50^{\text {th }}$ confirmed case. COVID-19 Dashboard by the Center for Systemic Science and Engineering (CSSE) at Johns Hopkins University. https://coronavirus.jhu.edu/data/cumulative-cases.

95 According to data collected by Bloomberg vaccine tracker as of April 3, 2021, more than 628 millon doses The latest rate was roughly 16.3 million doses a day have been administered across 150 countries. It's the biggest vaccination campaign in history. https://www.bloomberg.com/graphics/covid-vaccinetracker-global-distribution/ In his first set of presidential appointments, Obama brought into his administration five science Nobel prize winners and twenty-five members of the National Academies of Science, Engineering and Medicine. 